\title{
Refractory Bergmann type A bile leak: effect of gravity and tube sizing
}

We read with interest the paper by Massimiliano et al [1] which described a technique of "pulling-out of abdominal drain," which was placed close to the fistula site in patients with refractory Bergmann's type A leak to facilitate closure of fistula. Bile leak occurs in approximately $1 \%$ to $4 \%$ of patients after laparoscopic cholecystectomy and cystic duct stump is the most common site of leak [2,3].

Endoscopic retrograde cholangiopancreatography (ERCP) is the preferred therapeutic modality for management of bile duct leaks [4,5]. Endoscopic stenting with or without sphincterotomy decreases biliary pressure and minimizes flow through the leak. The technique of pulling out the drain tube described by the authors is effective and also a common practice at our center. However, we take two additional measures in patients with persistent leak after adequate endotherapy: 1. Replace the drain tube with a smaller-diameter tube (e.g. 16F nasogastric tube); and 2. Convert gravity-assisted drainage to a colostomy bag drainage to remove the effect of gravity.

These measures help close the fistula in almost all patients. Let's understand the physical principles of fluid dynamics behind these measures: (i) Fluid or air flows from high pressure zone to low pressure zone; and (ii) Compartments that are contiguous with each other have same pressure.

\section{Fluid (bile) flow in health and disease}

\section{In homeostasis}

Bile normally flows from bile duct to duodenum: hence biliary pressure $\left(\mathrm{P}_{\mathrm{bil}}=\right.$ $5-10 \mathrm{~cm}$ of $\mathrm{H}_{2} \mathrm{O}$ ) is higher than duodenal pressure $\left(P_{\text {duo }}\right)$. Because the alimentary canal is contiguous with external atmosphere, duodenal pressure will be similar or slightly higher than atmospheric pressure $\left(P_{\text {atm }}\right)$ probably due to presence of some peristaltic contrac-

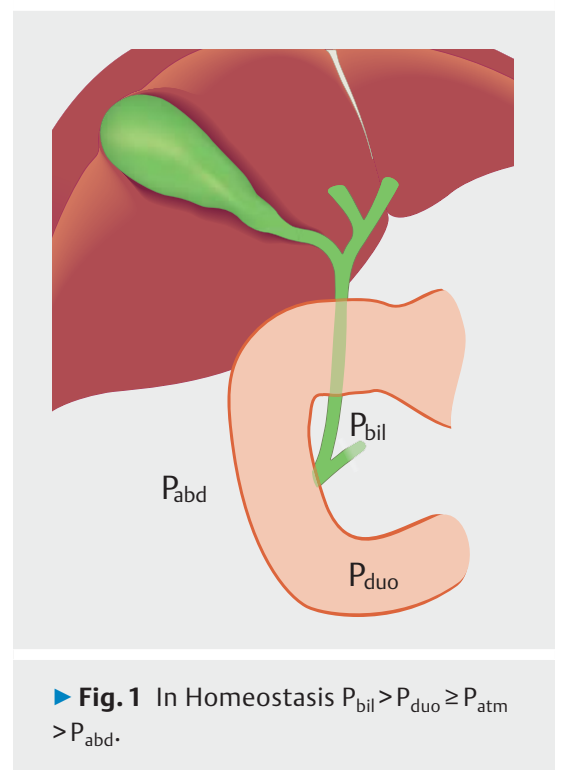

tions in the duodenum. Air normally flows from duodenum to abdominal cavity in perforation peritonitis and intraperitoneal pressure is normally considered negative, i.e. intraabdominal pressure $\left(\mathrm{P}_{\mathrm{abd}}\right)$ is lower than duodenal pressure ( $\mathbf{F i g}$. 1).

Hence, $P_{\text {bil }}>P_{\text {duo }} \geq P_{\text {atm }}>P_{\text {abd }}$

\section{In case of bile duct injury}

Since $\Delta \mathrm{P}_{\mathrm{bil}}-\mathrm{P}_{\mathrm{abd}}$ is higher than $\Delta \mathrm{P}_{\mathrm{bil}}-\mathrm{P}_{\mathrm{duo}}$, bile flows from biliary tract to the peritoneal cavity. But if it is undrained, intraabdominal pressure increases gradually and pressure difference decreases.

When biliary sphincterotomy is performed with biliary stenting, biliary pressure decreases and $\Delta \mathrm{P}_{\mathrm{bil}}-\mathrm{P}_{\mathrm{abd}}$ also decreases. Stenting helps in bypassing the leak site and allows it to heal. This is because the biliary tract is contiguous with the duodenum (after sphincterotomy) and also with abdominal cavity (fistula site), $P_{\text {bil }}=P_{\text {duo }}=P_{\text {abd }}$ ( $>$ Fig. 2).

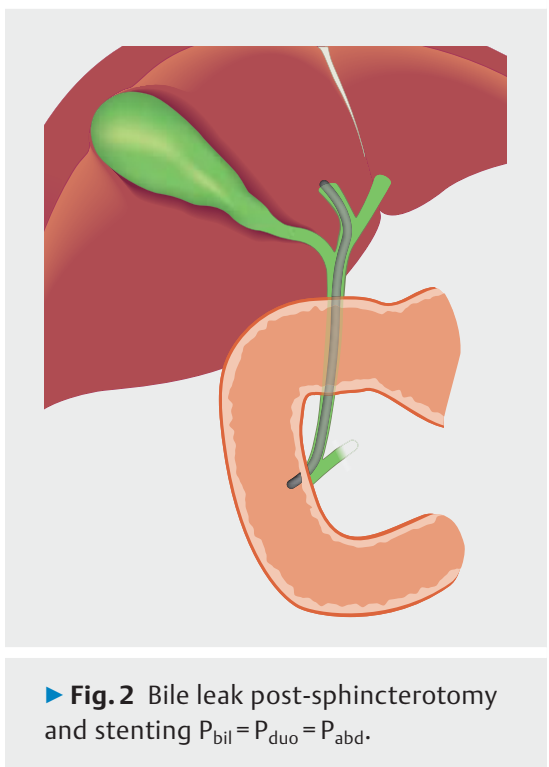

\section{Drain placement close to the biliary fistula in case of Bergmann's type A leak}

The drain acts as a conduit between the biliary tract and atmosphere and because $\Delta \mathrm{P}_{\mathrm{bil}}-\mathrm{P}_{\mathrm{atm}}$ will always be higher than $\Delta \mathrm{P}_{\text {bil }}-\mathrm{P}_{\text {duo }}$, the bile leak won't subside despite stenting, resulting in refractory bile leak ( $\triangleright$ Fig. 3 ).

\section{Farther drain displacement}

The drain acts as a conduit between the external atmosphere and abdominal cavity, and flow of fluid between the two compartments results from the pressure difference between the two. The resultant pressures in the compartments become equal i.e. $P_{b i l}=P_{d u o}=P_{a b d}$, hence the bile leak ceases ( $\triangleright$ Fig. 4 ).

\section{Drain size}

Drain size also matters because the flow of fluid is proportional to the 4th power of the radius ( $r 4$ ) of the drain tube (Poiseuile's law). Therefore, in patients with persistent leak despite sphincterotomy and/or stenting, a larger tube should be replaced by a small-diameter tube. 


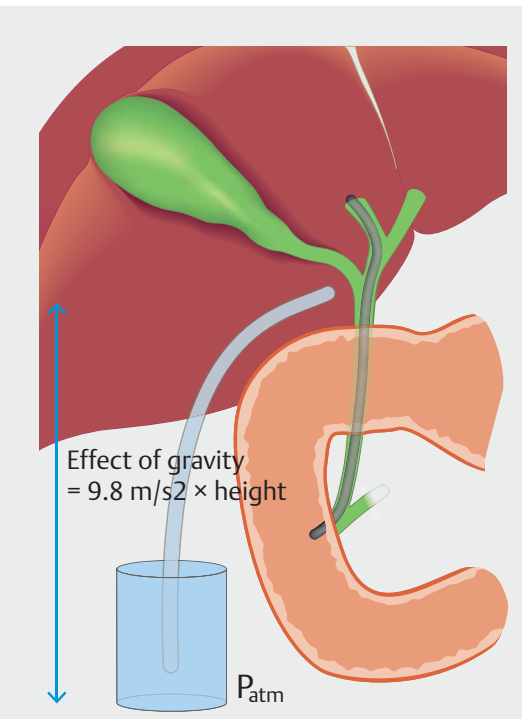

$\checkmark$ Fig. 3 When the, drain is close to the fistulous site, $\Delta \mathrm{P}_{\mathrm{bil}}-\mathrm{P}_{\text {atm }}$ will always be higher than $\Delta \mathrm{P}_{\text {bil }}-\mathrm{P}_{\text {duo }}$.

\section{Effect of gravity}

Gravity is an important determinant of drainage of fluid collections that is often ignored. When a patient is in bed with an abdominal drain hanging by the side to a lower level (close to the ground), the force of $\left(9.8 \mathrm{~m} / \mathrm{sec}^{2} \times\right.$ height) will add to external drainage. This can be eliminated if the drain is placed at the same level as the fistula by converting a drainage bag to an ostomy bag.

Thus, these two additional measures, i.e. replacing the drain tube with a smaller-diameter tube (e.g. $16 \mathrm{~F}$ nasogastric tube) and eliminating gravity-assisted drainage by converting to colostomy bag drainage help close the fistula in almost all patients.

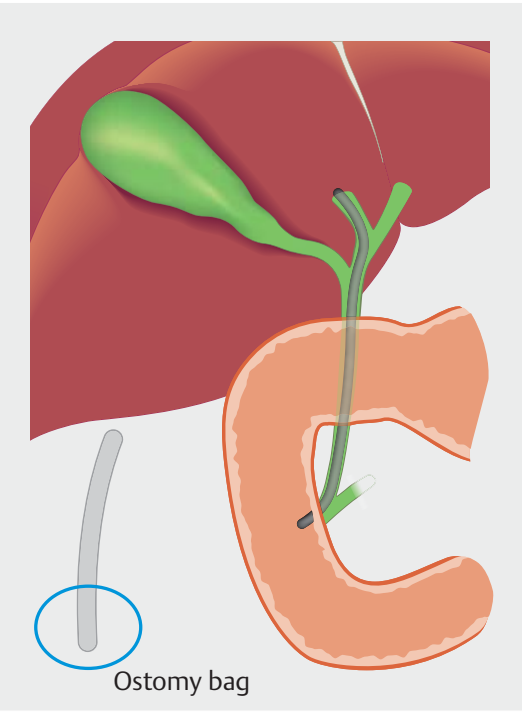

Fig. 4 When the drain is farther from the fistulous site, $P_{b i l}=P_{\text {duo }}=P_{\text {abd }}$.

\section{Competing interests}

The authors declare that they have no conflict of interest.

The authors

\section{Soumya Jagannath, Pramod Kumar Garg}

All India Institute of Medical Sciences,

Gastroenterology, New Delhi, Inida

Corresponding author

\section{Pramod Kumar Garg}

All India Institute of Medical Sciences Gastroenterology, Room No 3111, 3rd Floor, Academic Section Department of Gastroenterology, New Delhi 110029, India Fax: +91-1126588663

pkgarg@aiims.ac.in

\section{References}

[1] Mutignani M, Forti E, Larghi A et al. Refractory Bergmann type A bile leak: the need to strike a balance. Endosc Int Open 2019; 7: E264-E267

[2] Shawhan RR, Porta CR, Bingham JR et al. Biliary leak rates after cholecystectomy and intraoperative cholangiogram in surgical residency. Mil Med 2015; 180: 565569

[3] Viste A, Horn A, Øvrebø K et al. Bile duct injuries following laparoscopic cholecystectomy. Scand J Surg SJS Off Organ Finn Surg Soc Scand Surg Soc 2015; 104: $233-$ 237

[4] Adler DG, Papachristou GI, Taylor L] et al. Clinical outcomes in patients with bile leaks treated via ERCP with regard to the timing of ERCP: a large multicenter study. Gastrointest Endosc 2017; 85: 766-772

[5] Kim KH, Kim TN. Endoscopic management of bile leakage after cholecystectomy: a single-center experience for 12 years. Clin Endosc 2014; 47: 248-253

\section{Bibliography}

DOI http://dx.doi.org/10.1055/a-1075-2054

Endoscopy International Open 2020; 08: E523-

E524

(c) Georg Thieme Verlag KG

Stuttgart · New York

eISSN 2196-9736

\section{(우요}

